UDC 338.34:330.11

N. Podolchak, B. Chepil

\title{
OPTIMIZATION OF ADMINISTRATIVE MANAGEMENT COSTS
}

\begin{abstract}
It is important to determine the optimal level of administrative costs in order to achieve main targets of any enterprise, to perform definite tasks, to implement these tasks and not to worsen condition and motivation of the workers. Also it is essential to remember about strategic goals in the area of HR on the long run. Therefore, the main idea in using optimization model for assessing the effectiveness of management costs will be to find the minimum level of expenses within the given limits.
\end{abstract}

Key words: administrative costs, optimization model, levels of management.

Introdaction. Optimization involves finding the best index of the selected function in a particular opportunity set. Thus, the solution of the optimization model means finding its optimal solution or proving that there is no solution $[3,4,8]$. Optimization models are arranged in two categories: minimization problems and maximization problems. In our research, we will use the second category in order to find the optimal level of administrative costs for enterprises of gas industry.

Materials and methods. The peculiarity of forming the optimization model is determination of the efficiency unit. We must set the effectiveness of administrative costs for the selected unit. Many recent studies on construction and solution of optimization models have focused on choosing such measurement units as: product unit, unit of cost, unit of sown area etc. [5, 20]. In our case, it is not relevant to take into account these units of measurement as administrative costs are not included into cost of production [10]. We therefore propose to calculate administrative costs per head of the company. So, the function will look like this:

$$
F(x) \rightarrow \min ,
$$

where: $x$ - number of administrative employees.

However, the analysis of gas industry enterprises proves the importance of assessing the effectiveness of the administration costs on various levels of management, as there is a kind of asymmetry in terms of allocation of administrative expenses. Taking into account this problem we should specify the objective function as follows:

$$
a_{1} x_{1}+a_{2} x_{2}+a_{3} x_{3} \rightarrow \min ,
$$

where: $a_{1}, a_{2}, a_{3}-$ average amount of administrative costs per top manager, middle manager, low line manager, accordingly, thousands of UAN; $x_{1}, x_{2}, x_{3}$ - number of top, middle and low line managers accordingly.

Further investigations are needed to choose the most important limits to solve the optimization model. The choice of factors depends on the main objectives and personnel management strategies as well as administration costs of the company. Analysis of the domestic gas sector companies showed the following priority objectives for HR management and administrative costs, which can be displayed in the limits of the optimization model:

-developing chief executive officers, including their qualifications, practical skills, managerial skills and competence [14], active participation in retraining, advanced training and re-qualification;

- rejuvenating staff, particularly managers of industrial subdivisions;

-reducing losses caused by inaccurate management decisions and improving management decisions in the company;

-increasing the loyalty of chief executive officers $[1,6,9]$ and reducing the number and level of risk and risk of personnel activity [16];

-reducing the number of duplicate management structures, units and chiefs;

-improving the quality of labor input through the effective selection of personnel;

- reducing bureaucracy and corruption;

-increasing salaries and wages and reducing the number of employees;

-lowering the level of administrative employees turnover;

-reducing administrative costs to raise competitive capacity of a company.

Thus we represent the schematic model of optimization of management costs at the enterprises of gas industry (Fig. 1). 


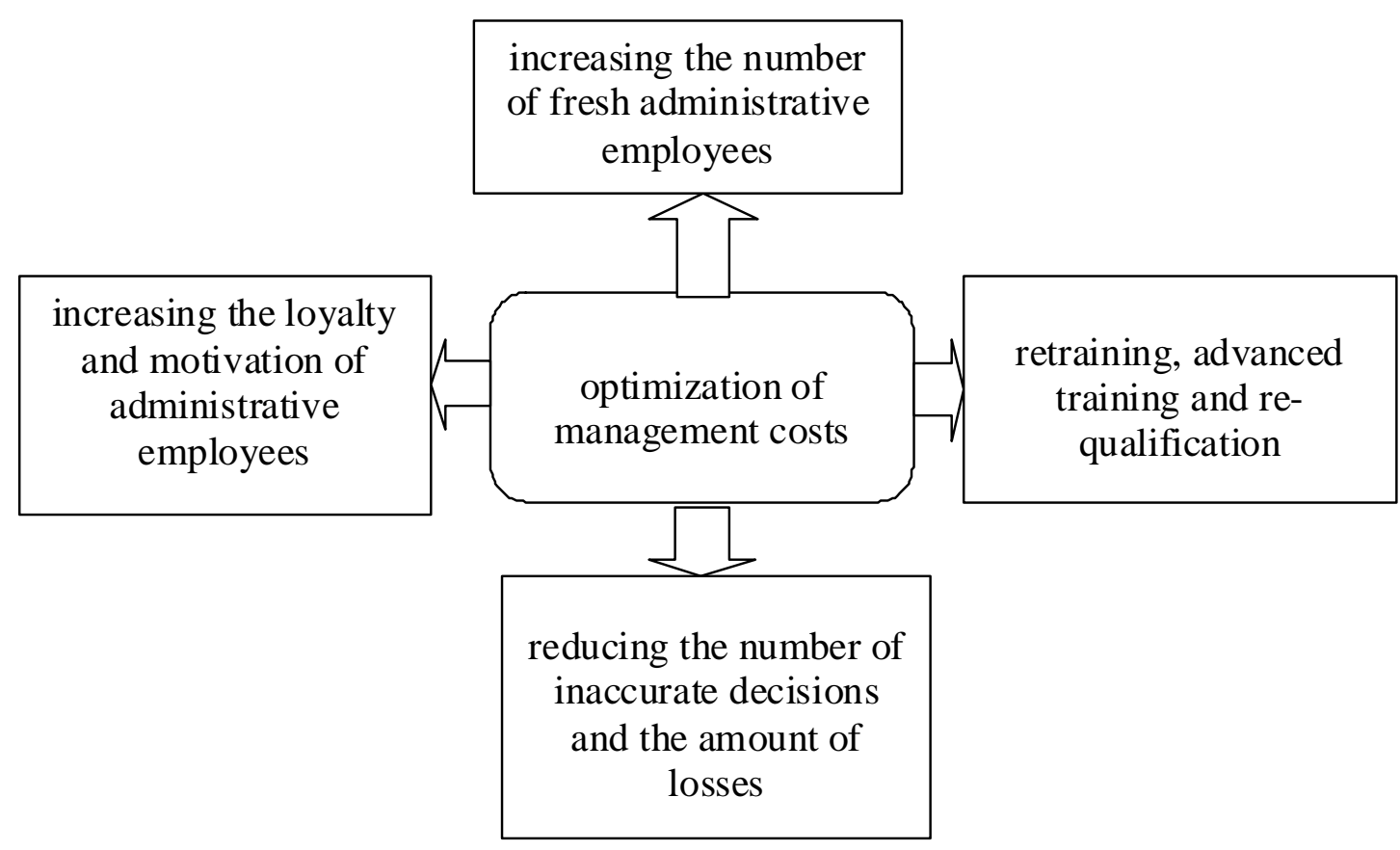

Fig.1. Directions of optimization of the enterprise management costs

The first limit to optimize administrative costs is a wages fund, which on the one hand, should be as low as possible in order to reduce administrative costs and on the other hand, it should be sufficient enough to meet the demands and to stimulate employees. The other aspects of the wages fund are to ensure sufficient loyalty of administrative employees, to avoid the loss of top managers, to create the decent staff reserve $[2,15]$. Thereafter, the wages fund function will have the following expression:

$$
b_{1} x_{1}+b_{2} x_{2}+b_{3} x_{3} \leq D
$$

where: $b_{1}, b_{2}, b_{3}$ - average administrative costs for wages per top manager, middle manager, low line manager accordingly, $D$ - wages fund.

According to the priority objectives in the field of personnel management and administrative management costs, it is important to ensure a continuous process of employees training. Any company budgets the expenditures on conducting training. These limits will be as follows:

$$
\begin{aligned}
& c_{1} x+c_{2} x+c_{3} x \leq K_{\max }, \\
& c_{1} x+c_{2} x+c_{3} x \geq K_{\min },
\end{aligned}
$$

where: $c_{1}, c_{2}, c_{3}$ - average management costs for training, advanced training and re-qualification of administrative employees; $K_{\min }, K_{\max }$ - expenditures on training, advanced training and requalification of administrative employees, minimum and maximum accordingly.
A significant amount of administrative losses is associated with the correction of errors and defects as a result of inaccuracy of management decision-making. Therefore, we should set the maximum allowed expenditure level aimed at eliminating wrong decisions and minimize the number of such decisions at various levels of management. The amount of additional costs of eliminating mistakes is calculated in terms of the managers' time spent multiplied by their average wages. The function will be as follows:

$$
e_{1} x_{1}+e_{2} x_{2}+e_{3} x_{3} \leq P
$$

where: $e_{1}, e_{2}, e_{3}$ - average management costs spent by top, middle and low line managers on elimination of the result of inaccurate management decisions; $P$ - highest possible management costs spent on elimination of the result of inaccurate management decisions.

Studies have shown that loyalty of staff has the direct impact on productivity and the result of the company's activities. It is therefore important to increase staff loyalty and set clear limits on the level of expenditures on the following measures:

$$
g_{1} x_{1}+g_{2} x_{2}+g_{3} x_{3} \leq L,
$$

where: $g_{1}, g_{2}, g_{3}$ - average expenditures for increasing the level of loyalty of top, middle and low line managers; $L$ - highest possible level of expenditures on increasing the level of loyalty of administrative employees of the company. 


\section{Optimization of administrative management costs}

In general, the proposed optimization model will be as follows:

$$
\begin{gathered}
a_{1} x_{1}+a_{2} x_{2}+a_{3} x_{3} \rightarrow \min \\
\left\{\begin{array}{l}
b_{1} x_{1}+b_{2} x_{2}+b_{3} x_{3} \leq D \\
e_{1} x_{1}+e_{2} x_{2}+e_{3} x_{3} \leq P \\
g_{1} x_{1}+g_{2} x_{2}+g_{3} x_{3} \leq L \\
c_{1} x_{1}+c_{2} x_{2}+c_{3} x_{3} \leq K_{\max } \\
c_{1} x_{1}+c_{2} x_{2}+c_{3} x_{3} \geq K_{\min }
\end{array}\right.
\end{gathered}
$$

Recently researchers have become increasingly unanimous in declaring that there is no balance between management costs at different levels of management. In particular, there are considerable and often unnecessary expenditures at the top level of management and significantly lower than they should be at the middle and low levels of management of gas industry enterprises. Especially, this imbalance is observed with the administrative costs of the state gas producing companies. Therefore, the objective function will remain the same as in the previous optimization model. Only limits will be changed for the optimization model:

$$
a_{1} x_{1}+a_{2} x_{2}+a_{3} x_{3} \rightarrow \min .
$$

The system will consist of six inequalities that set the maximum and minimum amount of administrative costs for the three levels of management - institutional, administrative and manufacturing $[11,12,13]$. Expenditures are planned and budgeted by the administration of the company. It is possible to establish the amount of administrative costs for each level of management by an expert way. Hereby, the amount of management costs at each level of management should provide staff development at this level and motivate managers to perform their tasks and goals, at the same time it should eliminate duplication, bureaucracy, corruption in the system of management at gas industry enterprises. The system of limits can be written as follows:

$$
\left\{\begin{array}{l}
l_{1} x_{1}+l_{2} x_{2}+l_{3} x_{3} \geq R_{1} \\
l_{1} x_{1}+l_{2} x_{2}+l_{3} x_{3} \leq R_{2}
\end{array},\right.
$$

where $R_{1}, R_{2}$ - minimum and maximum amount of administrative costs for providing the work of administrative employees at the institutional, administrative and manufacturing (technical) level; $l_{1}, l_{2}, l_{3}$ - amount of administrative costs per top manager, middle manager, low line manager, accordingly.
The process of balancing administrative costs can be carried out not only with aggregate expenditure per each management level but also with the elements of management costs to ensure stable work of each level of management at the enterprises of gas industry. Our research will explore how to balance the following administrative costs elements at three levels of management: material costs, wage bill, amortization, cost of social charges and other administrative costs. These costs at different levels of management will have different amount. Therefore, the proposed model will be as follows:

$$
\begin{gathered}
a_{1} x_{1}+a_{2} x_{2}+a_{3} x_{3} \rightarrow \min \\
\left\{\begin{array}{l}
d_{1} x_{1}+m_{1} x_{1}+z_{1} x_{1}+s_{1} x_{1}+f_{1} x_{1} \geq R_{11} \\
d_{1} x_{1}+m_{1} x_{1}+z_{1} x_{1}+s_{1} x_{1}+f_{1} x_{1} \leq R_{12} \\
d_{2} x_{2}+m_{2} x_{2}+z_{2} x_{2}+s_{2} x_{2}+f_{2} x_{2} \geq R_{21} \\
d_{2} x_{2}+m_{2} x_{2}+z_{2} x_{2}+s_{2} x_{2}+f_{2} x_{2} \leq R_{22} \\
d_{3} x_{3}+m_{3} x_{3}+z_{3} x_{3}+s_{3} x_{3}+f_{3} x_{3} \geq R_{31} \\
d_{3} x_{3}+m_{3} x_{3}+z_{3} x_{3}+s_{3} x_{3}+f_{3} x_{3} \leq R_{32}
\end{array}\right.
\end{gathered}
$$

where: $d_{1}, d_{2}, d_{3}$ - management costs for top, middle and low line managers' wages; $m_{1}, m_{2}, m_{3}-$ material management costs for providing the work of top, middle and low line managers; $z_{1}, z_{1}, z_{3}-$ depreciation of assets and facilities used for activities of top, middle and low line management; $s_{1}, s_{2}, s_{3}$-costs on social payroll at top, middle and low line management levels; $f_{1}, f_{2}, f_{3}$ - other operation management costs of top, middle and low line managers.

We should also develop databases to record administrative expenses. Thus, the aim of applying $\mathrm{ABC}$ analysis tools to administrative expenses is to allocate costs according to management activities and to identify factors that affect these costs [7, 19]. Thereby, $\mathrm{ABC}$ analysis, also called functional and value analysis [17], allows us to track the connections between expenditures and their reasons.

After examining peculiarities of gas industry enterprises operation, for distributing expenses to corresponding centres it is reasonable to set the appropriate grouping of management departments done according to similarity of their functions. We can specify the following centres: the financial and economic centre, the centre of production, the centre of legal aid and monitoring, the research centre, the centre of production service, the centre of personnel management. 


\section{N. Podolchak, B. Chepil}

1. The financial and economic centre (accounting department, planning and economic department, financial department, investment department);

2. The centre of production (manufacturing department, technical department, drilling department, the department of capital construction);

3. The centre of legal aid and monitoring (law department, safe-custody department, internal audit department);

4. The centre of production service (department of chief engineer, logistics department, administration department and secretariat, department of power and water supply, department of occupational safety and health, department of information support and computer service);

5. The research centre (department of geology, laboratories, budgeting department);

6. The centre of personnel management (department of work organization and wages, personnel department).

It is important to identify factors that impact the expenses on the selected centers in the process of their formation. The factors of expenditures of the finance and economic centre can be the number and size of reports (administrative and financial), the number of documents that need processing, organization of record-keeping, the number of mistakes and errors made by employees and identified in the process of different revisions, the amount of fines imposed due to the employees' errors.

The factors of expenditures of the centre of production can be the number of oil wells, the regional location of oil fields, and the production volume of gas, oil and other related products. It is necessary to introduce the value coefficient of complexity and the level of infrastructure development of the area where energy resources are mined.

The factors of expenditures of the centre of legal aid and monitoring can be payment discipline, reliability of suppliers and contractors, the level of prevention of theft and abuse, the amount of leakage of commercial information and losses caused by it, the level of physical and psychological protection of workers (measured in points obtained by surveys).

The factors of expenditures of the centre of production service can be the number of suppliers, the regional location of facility, the size of suppliers and supply chains length, width of supply chains, infrastructure of the area, the number of discounts and amount of resource savings obtained as the result of discounts.

The factors of expenditures of the research centre can be the number of projects, the number of objects of geological research, the complexity of geological research, peculiarities of the projects implementation (joint activity, economic method, and outsourcing), the number of confirmed reserves and successful projects.

The factors of expenditures of the centre of personnel management can be the number of personnel, qualifications and structure of staff, personnel turnover rate, work experience in the company and the industry, the amount of documentary support for every employee, the number of training programs and professional development courses, their frequency and methods of conducting (internal, inviting outside expert trainers and mixed), the number of social programs and staff loyalty development programs.

So, having divided total administrative costs into the appropriate groups of centres, we may follow their dynamics monitoring the factors of expenditures. For example, we may trace the change of expenditures of the finance and economic centre in case of introducing a new accounting program or electronic document control, the change of expenditures of the centre of production service in case of temporary closing down some wells, the change of expenditures of the centre of personnel management in case of changing the number of employees etc. In addition, this division will help to optimize administrative costs, to balance them between centres, to save costs, to improve the organizational management structure and to promote company's development.

Certainly, the expenditures of the centres cannot be proportionally altered following changes in the factors of expenditures, and it is obvious that any change takes time. The changes happen with some delay, there are time lags. It is important to consider the time factor while finding the connection between the amount of expenditures and factors affecting them [18].

It is important to create a sharp system of organizational and informational support to administer management costs by responsibility centres. We suggest appointing responsible persons to the centres to ensure a high level of administration (they can be deputy chiefs in functional areas). They should be in charge of performing system monitoring of the expenses level and dynamics (preliminary, current and final) following changes in the factors related to the centres of administering management costs.

The proposed division into centres of administering management costs can be used to construct 


\section{Optimization of administrative management costs}

an optimization model to balance administrative costs. The criterion of dividing the administrative costs will be determined by the structure and quality of the staff in each of the proposed centres. Therefore, the proposed model will be as follows:

$$
q_{1} y_{1}+q_{2} y_{2}+q_{3} y_{3}+q_{4} y_{4}+q_{5} y_{5}+q_{6} y_{6} \rightarrow \min ,(12)
$$

where: $q_{1}, q_{2}, q_{3}, q_{4}, q_{5}, q_{6}$ - average amount of management costs per workers in the finance and economic centre, the centre of production, the centre of legal aid and monitoring, the centre of production service, the research centre and the centre of personnel management; $y_{1}, y_{2}, y_{3}, y_{4}, y_{5}, y_{6}-$ average number of administrative employees in the finance and economic centre, the centre of production, the centre of legal aid and monitoring, the centre of production service, the research centre and the centre of personnel management.

Limits of the optimization model should be formed according to the expenditures on activities of each of the established centres for administering management costs. Therefore, the system of limits will be as follows:

$$
\left\{\begin{array}{l}
d_{c 1} y_{1}+m_{c 1} y_{1}+z_{c 1} y_{1}+s_{c 1} y_{1}+f_{c 1} y_{1} \leq \Psi_{1} \\
d_{c 2} y_{2}+m_{c 2} y_{2}+z_{c 2} y_{2}+s_{c 2} y_{2}+f_{c 2} y_{2} \leq \Psi_{2} \\
d_{c 3} y_{3}+m_{c 3} y_{3}+z_{c 3} y_{3}+s_{c 3} y_{3}+f_{c 3} y_{3} \leq \Psi_{3} \\
d_{c 4} y_{4}+m_{c 4} y_{4}+z_{c 4} y_{4}+s_{c 4} y_{4}+f_{c 4} y_{4} \leq \Psi_{4} \\
d_{c 5} y_{5}+m_{c 5} y_{5}+z_{c 5} y_{5}+s_{c 5} y_{5}+f_{c 5} y_{5} \leq \Psi_{5} \\
d_{c 6} y_{6}+m_{c 6} y_{6}+z_{c 6} y_{6}+s_{c 6} y_{6}+f_{c 6} y_{6} \leq \Psi_{6}
\end{array}\right.
$$

where: $d_{c 1}, d_{c 2}, d_{c 3}, d_{c 4}, d_{c 5}, d_{c 6}-$ administrative expenses on salaries of managers in the finance and economic centre, the centre of production, the centre of legal aid and monitoring, the centre of production service, the research centre and the centre of personnel management; $m_{c 1}, m_{c 2}, m_{c 3}, m_{c 4}$, $m_{c 5}, \quad m_{c 6}$ - financial management costs for providing the work of administrative employees in the finance and economic centre, the centre of production, the centre of legal aid and monitoring, the centre of production servicing, the research centre and the centre of personnel management; $z_{c 1}$, $z_{c 2}, z_{c 3}, z_{c 4}, z_{c 5}, z_{c 6}-$ depreciation of assets and facilities used for the activities of administrative employees in the finance and economic centre, the centre of production, the centre of legal aid and monitoring, the centre of production servicing, the research centre and the centre of personnel management; $s_{c 1}, s_{c 2}, s_{c 3}, s_{c 4}, s_{c 5}, s_{c 6}-$ costs on social payroll for administrative employees in the finance and economic centre, the centre of production, the centre of legal aid and monitoring, the centre of production servicing, the research centre and the centre of personnel management; $f_{c 1}$, $f_{c 2}, f_{c 3}, f_{c 4}, f_{c 5}, f_{c 6}$ - other management costs for providing the work of administrative employees in the finance and economic centre, the centre of production, the centre of legal aid and monitoring, the centre of production servicing, the research centre and the centre of personnel management; $\Psi_{1}, \Psi_{2}, \Psi_{3}, \Psi_{4}, \Psi_{5}, \Psi_{6}-$ maximum level of management costs to provide the work of the finance and economic centre, the centre of production, the centre of legal aid and monitoring, the centre of production servicing, the research centre and the centre of personnel management.

In such a model it should also be established the minimum amount of management costs that would ensure the necessary tasks and work performance. Therefore, the model takes the following form:

$$
\left\{\begin{array}{l}
\chi_{1} \leq d_{c 1} y_{1}+m_{c 1} y_{1}+z_{c 1} y_{1}+s_{c 1} y_{1}+f_{c 1} y_{1} \leq \Psi_{1} \\
\chi_{2} \leq d_{c 2} y_{2}+m_{c 2} y_{2}+z_{c 2} y_{2}+s_{c 2} y_{2}+f_{c 2} y_{2} \leq \Psi_{2} \\
\chi_{3} \leq d_{c 3} y_{3}+m_{c 3} y_{3}+z_{c 3} y_{3}+s_{c 3} y_{3}+f_{c 3} y_{3} \leq \Psi_{3} \\
\chi_{4} \leq d_{c 4} y_{4}+m_{c 4} y_{4}+z_{c 4} y_{4}+s_{c 4} y_{4}+f_{c 4} y_{4} \leq \Psi_{4} \\
\chi_{5} \leq d_{c 5} y_{5}+m_{c 5} y_{5}+z_{c 5} y_{5}+s_{c 5} y_{5}+f_{c 5} y_{5} \leq \Psi_{5} \\
\chi_{6} \leq d_{c 6} y_{6}+m_{c 6} y_{6}+z_{c 6} y_{6}+s_{c 6} y_{6}+f_{c 6} y_{6} \leq \Psi_{6}
\end{array}\right.
$$

where: $\chi_{1}, \chi_{2}, \chi_{3}, \chi_{4}, \chi_{5}, \chi_{6}-$ minimum level of management costs to provide the work of the finance and economic centre, the centre of production, the centre of legal aid and monitoring, the centre of production servicing, the research centre and the centre of personnel management.

We will find the solution of this model using the data of the gas manufacturing department "Lvivhazvydobuvannya". The function with the data will be written as follows:

$$
\begin{aligned}
& 156457 y_{1}+160963 y_{2}+129917 y_{3}+ \\
& 141060 y_{4}+146912 y_{5}+177716 y_{6} \rightarrow \min \text {, } \\
& \left\{\begin{array}{l}
3730904 \leq 156457 y_{1} \leq 5577701 \\
2971625 \leq 160963 y_{2} \leq 4442579 \\
1299171 \leq 129917 y_{3} \leq 1942261 \\
4991342 \leq 141060 y_{4} \leq 7462057 \\
2373190 \leq 146912 y_{5} \leq 3547919 \\
956933 \leq 177717 y_{6} \leq 1430616
\end{array} .\right.
\end{aligned}
$$

Results. The solution of the optimization model makes it possible to establish the crucial number of employees for each of the centres of administration 


\section{N. Podolchak, B. Chepil}

management costs: the finance and economic centre 23 persons, the center of production - 18 persons, the centre of legal aid and monitoring - 10 persons, the centre of production servicing - 35 persons, the research centre -16 persons, the centre of personnel management -6 persons.

Our research has proved that this number of administrative employees will lead to reduction of expenditures and the number of managerial staff by combining the individual functions and optimization of interaction processes. The quality and amount of work performed will not be reduced, and in some centres will be increased by improving the social and psychological environment, eliminating duplication of functions, decentralizing operations and improving productivity. Our research has revealed the staff reduction being as follows: the finance and economic centre -8 persons, the centre of production 4 persons, the centre of legal aid and monitoring 4 persons, the centre of production servicing 11 persons, the research centre -5 persons, the centre of personnel management -1 person. Total staff reduction may reach 28 and management costs may be reduced by 30 .

Conclusions. Optimization models will enable managers to balance the functioning of different levels of administrative employees, to optimize management costs, and thus to increase productivity and staff loyalty, to reduce economic risks and personnel turnover rate, to develop staff reserve and to improve other financial and economic indicators of enterprises. We have elaborated the model of optimization of management costs spent by top, middle and low line managers, composed the optimization model for three levels of management institutional, administrative and manufacturing. Using $\mathrm{ABC}$ analysis, another optimization model has been formed to administer management costs on the basis of specialized centres: the finance and economic centre, the centre of production, the centre of legal aid and monitoring, the centre of production servicing, the research centre, the centre of personnel management.

\section{References}

1. Allen N. Affective, Continuance, and Normative Commitment to the Organization: An Examination of Construct Validity / N. Allen, J. Meyer // Journal of Vocational Behavior. - 1996. - Vol. 49. - P. 252-276. (USA).

2. Atkinson A. Management Accounting / A. Atkinson. 3rd edition, St. Petersburg.: Williams. - 2004. (Russia).

3. Berezhnaya E. Mathematical modeling methods of economic systems. 2nd ed. / E. Berezhnaya, V. Berezhnoy. Moscow: Finance and Statistics. - 2006. (Russia).
4. Bonini C. P. Quantitative Analysis for Managemen / C. P. Bonini, W. H. Hausman, H. Bierman. - The McGraw-Hill. - 1997. (USA).

5. Cooper R. Activity Based Costing: practical application / R. Cooper, R. Kaplan. - Moscow: Williams. 2008. (Russia).

6. Dominyak B. Organizational loyalty: basic approaches / B. Dominyak. HR Manager. - 2006. - № 4, 34-40. (Russia).

7. Feshchur R. V. Econometrics (Part 1. Mathematical Foundations modeling)/R. V. Feshchur, I. I. Korkuna, A. O. Bosak, O. U. Grigoriev. - Lviv: Publishing House of National University Lviv Polytechnic. 1998. (Ukraine).

8. Garasym P. Financial, management and tax accounting in companies / P. Garasym, G. P. Zhuravel, P. Y. Khomyn. - Ternopil. - 2003. (Ukraine).

9. Harska K. Trustworthiness and loyalty of staff / K. Harska. St. Petersburg: Peter, 496. - 2003. (Russia).

10. Holov S. V. Management Accounting. Textbook 2nd ed. /S. V. Holov. - Kyiv: Libra. - 2004.

11. Kuzmin O. E. Fundamentals of Management: Textbook / O. E. Kuzmin, O. G. Melnyk. - Kyiv: Akademvydav. - 2007. (Ukraine).

12. Mescon M. Fundamentals of Management/M. Mescon, M. Albert, F. Khedouri: Publishing house: Delo. (USA). - 1997

13. Mihlyayev M. O. Wages as a major component of the mechanism of motivation management personnel / M. O. Mihlyayev. - 2012. Scientific Bulletin - Odessa National Economic University. National Association of Young Scientists. Science: economics, political science. 15, 27-37. (Ukraine)

14. Oleksiv I. The formation of the system of evaluation of enterprise workers' competence / I. Oleksiv, G. Mykhailyak // Econtechmod. An International Quarterly Journal on Economics in Technology, New Technologies and Modelling Processes. № 3, Vol. 2, 53-57. (Poland). - 2013.

15. Parsons Talcott. [Electronic resource]. Mode of access: URL http://ru.wikipedia.org/wiki / Parsons Talcott. (USA).

16. Podolchak N. Y. Improve-ment of motivation of employees considering the risk / N. Y. Podolchak. Publishing House of National University Lviv Polytechnic. - 2011. - № 714, 139-148. (Ukraine)

17. Prodyus Y. P. Management HR / Y. P. Prodyus, T. A. Vladimirov, D. V. Zaporozhan and others. Odessa: OMU. (Ukraine). - 2001.

18. Tuneev M. M. Economic-Mathematical Methods in Planning and organization of agricultural production / M. M. Tuneev, V. F. Suharukov. - Moscow: Statistics. (Russia). -1985.

19. Ukrainian accounting standard 16 "Costs", approved by the Ministry of Finance of Ukraine 31.12.1999 r. Number 318 //zakon1.rada.gov.ua. (Ukraine)

20. Vitlinskiy V. Modelling economy. - Kyiv: MBK. 2003. 